Journal of Tourism Management Research

2021 Vol. 8, No. 1, pp. 88-100

$\operatorname{ISSN}(e): 2313-4178$

$\operatorname{ISSN}(p): 2408-9117$

DOI: $10.18488 /$ journal.31.2021.81.88.100

(C) 2021 Conscientia Beam. All Rights Reserved.

check for
updates

\title{
INSTITUTIONAL ADVANCEMENT AS A REACTION TO THE COVID-19 PANDEMIC IN THE TOURISM CITY OF SAMARKAND, UZBEKISTAN
}

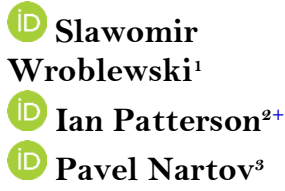

Article History

Received: 20 January 2021 Revised: 24 February 2021 Accepted: 29 March 2021 Published: 26 April 2021

\section{Keywords}

Tourism city

COVID-19 pandemic

Samarkand

Uzbekistan

Institutional theory

Trust.

\author{
${ }^{\prime}$ PhD, Dean of Tourism Management Faculty, Silk Road International \\ University of Tourism, 17 University Boulevard, Samarkand, Samarkand, \\ Uzbekistan. \\ Email:wroblewskisj@gmail.com Tel:+998902872527 \\ ${ }^{2} \mathrm{PhD}$, Visiting Professor, Silk Road International University of Tourism, \\ 17 University Boulevard, Samarkand, Uzbekistan. \\ Email:ianpatterson75@outlook.com \\ ${ }^{3}$ Nicolaus Copernicus University, Torun, Poland. \\ Email:p.ju.nartov@gmail.com Tel:+77059158007
}

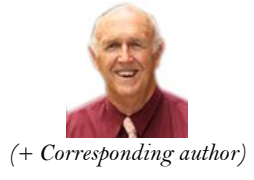

ABSTRACT

The aim of this study is to determine the effects of COVID-19 pandemic on the city of Samarkand, Uzbekistan and by adopting an institutional approach, to generate solutions that might contribute to the future development of the tourism and hospitality industries. A computer-based survey was developed and administered online using the Google Forms platform. The survey consisted of the following questions: (1) reactions to the pandemic's influence on tourism (2) short-term recovery plans (3) longterm challenges, and (4) demographic characteristics of respondents. Surveys were distributed to email addresses of over 150 tourism managers and employees in Uzbekistan in June, 2020. A final total of 77 responses were found acceptable for analysis. Findings identified a number of institutions used as a response to the pandemic: additional state support for entrepreneurs, webinars, new investment projects, post-crisis measures, actions aimed at improving the product, and marketing campaigns to promote the tourism product. Several initiatives were instituted by Samarkand Regional Government including support for entrepreneurs and small business owners through start-up investment projects. However, overall, a lack of trust was shown between the tourism owners/providers and regional government with the majority of owners preferring to solve their own problems that were created as a result of the pandemic.

Contribution/Originality: This paper uses an institutional framework for the analysis of the tourism industry in Samarkand, Uzbekistan which is unique and different from other current mainstream approaches. In addition it suggests solutions about how governments can use tourism as a major tool for the 'start-up' of the economy after COVID-19.

\section{INTRODUCTION}

Coronavirus or the COVID-19 pandemic has been described as the most defining global health crisis of our time, and the greatest challenge the world have faced since World War II (United Nations Development Program, 2020). Coronavirus disease (COVID-19) has been defined by WHO as an infectious disease caused by a newly discovered coronavirus. The COVID-19 virus spreads primarily through droplets of saliva or discharge from the nose when an infected person coughs or sneezes. On March 11, 2020, the World Health Organization 
announced that the COVID-19 outbreak was officially a pandemic. At the time of writing (April 18 2021), globally there have been 140 million confirmed cases of COVID-19, and 3,023,911 deaths.

This paper focuses on the effects of COVID-19 pandemic on the tourism industry in the Republic of Uzbekistan and specifically the city of Samarkand, a city with a very strong tourism profile. The second goal is to investigate the role of institutional theory (and its norms, practices and patterns of social relationships), to determine how the tourism industry can change its organizational structures to connect with the broader social and cultural environment post pandemic.

The significance of this paper is that we were able to show how Samarkand, as a neonate destination can be seen as a representative case study, and to provide an institutional framework for the analysis of the tourism industry in Samarkand which is unique and different from other current mainstream approaches. That is, to suggest solutions about how governments can use tourism as a major tool for the start up of the economy after COVID-19, and to assist as a major creator of jobs for the local economy.

\section{LITERATURE REVIEW}

\subsection{The Effects of COVID-19 on a Global Society}

The chronic nature of the coronavirus disease (COVID-19) has created problems that are associated with people's physical, mental and psychological wellbeing. Aslam, Awan, Syed, Kashif, and Parveen (2020) classified feelings and emotions that were based on news headlines relating to COVID-19. These emotions related to feelings of fear, and anger, as well as anticipation and trust. The COVID-19 pandemic has also produced feelings of shock, confusion, disbelief about what people felt they were up against. For many people, anxiety was high on their list as a result of the pandemic (Mayo Clinic Health System, 2020).

At first, COVID-19 created feelings of fear among employees and other stakeholders in the work place because of the massive scale of the outbreak and its sheer unpredictability that has made it very challenging for executives to respond to this crisis. This has resulted in a high degree of uncertainty that has given rise to disorientation, a feeling of a loss of control, and strong emotional disturbances.

The World Bank described the pandemic as representing the largest economic shock the world has experienced in decades. In its Global Economic Prospects Report (2020), it stated that the baseline forecast envisioned a 5.2\% contraction in global GDP in 2020, which was the deepest global recession in decades. In the long term the World Bank forecast that the pandemic..."is expected to leave lasting scars through lower investment, an erosion of human capital, lost work and schooling and the fragmentation of global trade and supply linkages".

As a result, the factors associated with psychological, organizational, economic and fiscal stress are all examples of elements of institutional change that have occurred in the market place which have been caused by the COVID19 pandemic. In addition, all these major changes have combined resulting in the collapse of the global tourism industry.

\subsection{Institutional Theory}

On the basis of economics, the introduction of the notion of institution has been commonly attributed to Veblen (1899). Other scholars who wrote about institutions were the fathers of sociology - Durkheim and Weber. Despite the long tradition of research on institutions, there is still no single widely accepted definition of the concept of an institution. However, the most well-known and accepted is the definition by North (1990) who stated that, "Institutions are the rules of the game in society, or more formally, they are invented constraints that define social interactions" (p. 3).

Among institutions, there are informal and formal institutions (norms, rules) that differ, inter alia, in their susceptibility to deliberate change (See Figure 1). North pointed out that if formal institutions (e.g., legal regulations) did not coincide with, or even contradict informal institutions the costs of introducing changes was 
very high. Therefore, when formal and informal institutions are linked to the tourism market, interact with each other their coexistence and development will favor the implementation of the expected changes, as part of the response to a crisis caused by a pandemic.

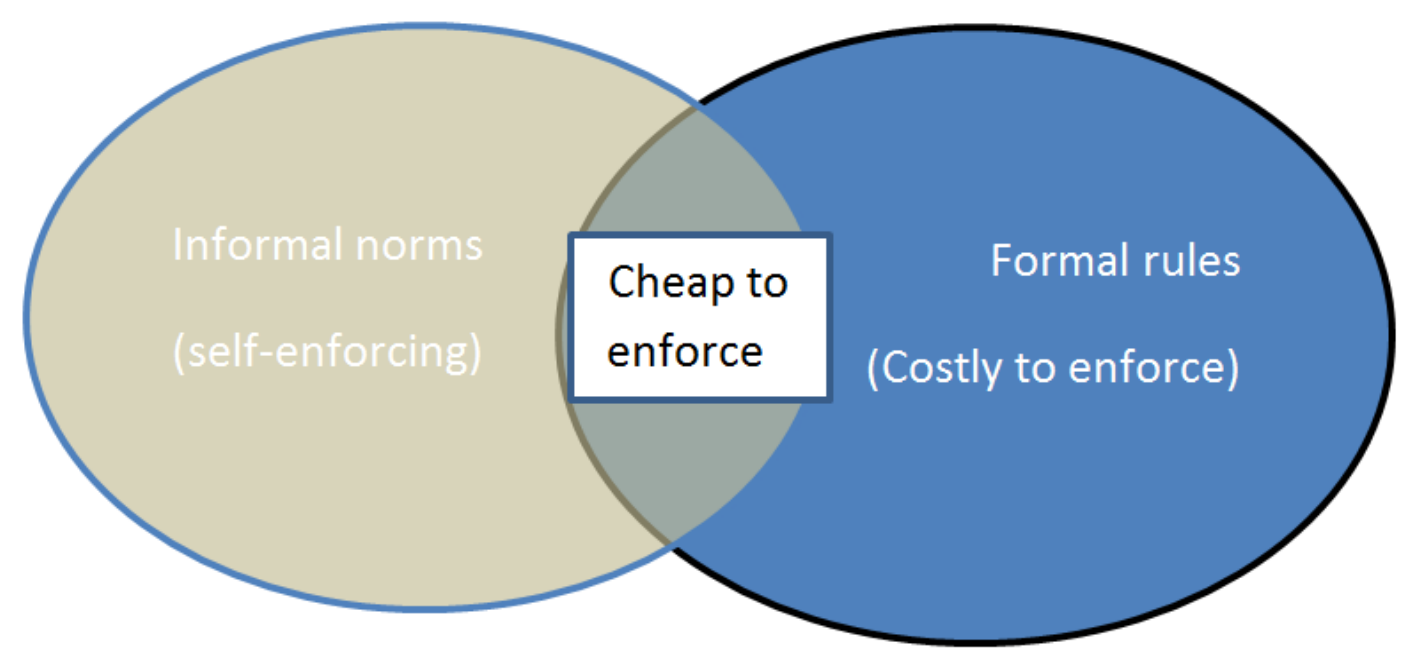

Source: Sautet (2005).

Figure-1. The relationship between informal and formal institutions.

The theory of transaction costs which was originally developed in Coase (1991) and further developed by Williamson (1985). This theory provides the foundation for understanding the reasons behind viewing enterprises as a special form of an institution. This theory is a key element of the theory of institutionalism, because it justifies the need and mechanisms for creating institutions which allow for more effective functioning in the market.

Such assumptions can therefore also be adopted for the tourism market and need to be considered in this article. Williamson (1985) suggested the need to distinguish four levels of economic analysis: micro (current changes); mezzo (period of change up to 10 years); macro (perspective up to 100 years) and mega (perspective of longer than a 100 years).

\subsection{Uzbekistan}

Uzbekistan is a central Asian country that is surrounded by five landlocked countries: Kazakhstan to the north, Kyrgyzstan to the northeast, Tajikistan to the southeast, Afghanistan to the south and Turkmenistan to the southwest. In 1991 it seceded from the Soviet Union and was declared an independent republic. Uzbekistan is now a secular, unitary constitutional republic consisting of 12 provinces (vilayats) and one autonomous republic Karakalpakstan. The capital and largest city in Uzbekistan is Tashkent which is situated in the Eastern part of the country (Encyclopedia of the Nations, n.d). In Uzbekistan, the first case of COVID-19 was reported on March 15, 2020 and it soon began to spread. Presently (April 18, 2021) there have been 86,338 confirmed cases, 83,838 have recovered and there has been 636 deaths.

\subsection{Samarkand - A Tourism City}

Samarkand is one of the longest-inhabited cities in the world. The ancient city of Marakanda was founded in the 6th century BC. In the 4th century BC, the city was captured by Alexander the Great. The period of development came thanks to the creation of the silk route connecting Europe and China, as a result of which Samarkand became the largest city in Central Asia. In 712 it was conquered by the Arabs who introduced the Islamic religion. At that time, it also became a papermaking center, from which paper came to Europe for the first time. In 1220 it was demolished by Genghis Khan. Only a small part of the city's population survived the Mongol invasions. In the years 1369-1405, Samarkand was the capital of Amir Timur's state stretching from India to 
Turkey. In 36 years, the ruler built a new city and brought artists and craftsmen from all over the empire to it. Under the rule of the Timurides, the city regained its former importance and became one of the most famous centres of Islamic culture, science and art. Samarkand experienced its greatest heyday in the 15 th century during the reign of Ulugh Beg, Timur's grandson. Compared to previous decades, the stable situation of the state meant that Ulugh Beg began to invest in the scientific and cultural development of his capital city. On his initiative, an astronomical observatory and madrassas were built as traditional schools of higher education in the Islamic world. These madrasses are now known as Registan Square, one of the major tourist attractions of Samarkand.

Samarkand (Samarqand) is the second largest city in Uzbekistan, and is regarded as one of the major tourism cities in Uzbekistan. For decades, Samarkand has been seen as one of the main attractions for attracting tourists, both on a national scale, from neighboring countries and foreign tourists from Europe and Asia. Since 2001, the city has been included into the UNESCO World Heritage List as "Samarkand - the crossroads of cultures". In 2019, 227.3 thousand people visited Samarkand. One of the most important reasons for these trips was to visit the historical and unique mosques and monuments. Other reasons for coming to Samarkand included visiting its places of worship, and the attraction of its local cuisine, especially the widely known and regarded plov and local breads.

\subsection{Effects of COVID-19 on the Tourism Industry in Samarkand}

In 2020, the Department for Tourism Development of the Samarkand region reported that the number of tourists visiting the region has dropped sharply due to the coronavirus pandemic. A comparison of the corresponding period is meaningful here: in 2019, 227.3 thousand new jobs were added, while in 2020 only 49.5 thousand. This decrease also applied to local visitors, of which there were 1 million 206 thousand, however currently only 286 thousand visited Samarkand. The tourism sector was one of the worst affected by the crisis as a result of the pandemic, resulting in 331 tourism enterprises closing and 4,530 people becoming temporarily unemployed (Samarkand Regional Government, 2020).

\subsection{Government Initiatives to Assist the Tourism Industry in Samarkand}

According to Samarkand Regional Government (2020) local authorities have undertaken numerous measures to support the tourism sector. These activities include the deferral of debt repayments due to loans granted to tourism industry enterprises was extended until October 1, 2020; hoteliers were exempt from paying taxes on land and property until the end of 2020 ; the social tax rate had been reduced from the current $12 \%$ to $1 \%$; solutions for granting loans and subsidies were introduced, of which 268 economic entities had expressed a desire to take advantage of, and the difficulty in collecting documents was being closely monitored by local authorities; partial cofinancing was provided for innovative projects such as information services, gastronomy for foreign guests, preparation of souvenirs; assistance was provided for those who paid out their earlier loans (20 business entities), construction of 10 new accommodation facilities in cost-saving technologies and the renovation of three existing hotels were supported.

At the same time, in order to restore the effective functioning of the tourism sector as soon as possible after the sanitary and epidemiological situation in the country had stabilized, the "Uzbekistan: Guaranteed Safe Travel" program was implemented, which involved offering safe facilities that were entered in a special register by trained staff.

Furthermore, in order to further develop different types of special interest tourism, the Samarkand authorities devoted each week to an analysis of the tourist potential of the Samarkand region for further promotion. As a result, in the first week in August, 2020, over 100 'Passports' (or descriptions) of gastronomic tourist facilities, and an album about gastronomic tourism in the Samarkand region was distributed. During the next week on Medical Tourism, over 50 passports of medical tourism facilities were collected and an appropriate catalogue was prepared. An example of the high potential of this field, is the region of the city of Nurbulak where as many as 27 medical 
centers are located that are visited annually by 300 thousand people. As part of the "Craftsmen Week", descriptions of the activities of 325 craftsmen specializing in tourism were prepared.

The pandemic period has also been used to plan further initiatives in Samarkand. By the end of 2021, it is planned to implement 54 investment projects in the field of tourism and to create 1,321 jobs. In the historic center of Samarkand, work is underway to create gastronomic areas. Two locations (mahalla "Konigil" and mahalla "Bogibaland") have been selected as an exemplary type of tourist village. All stakeholders and the local community are involved in the implementation of these projects.

Samarkand is also regarded as a destination for religious tourism, the so-called "zoriyat". In order to develop pilgrimage tourism around the "Imam al-Bukhari" complex of the Payarik region, it is planned to create catering and accommodation facilities and a shopping center fully complying with the halal standard (compliant with the requirements of the Muslim religion). So far, seven large 3-star and 4-star hotels are under construction which are fully meeting Halal standards. This should create about 150 jobs and extend the stay of many pilgrim tourists for longer periods of time.

In addition, work has started on the organization of spa zones in the mountain regions around Samarkand. In order to determine the current state of health resorts and sanatoriums in the region, a complete inventory was made. Currently, there are 30 spa zones in the Samarkand region with a total daily capacity of 4,700 people. Another plan has been commissioned as part of the "Okbuiro Garden" project, which includes 20 seasonal and 20 year-round houses, a swimming pool, a playground and conditions for conducting concerts and outdoor performances.

\section{RESEARCH METHODS}

Based on these developments, a team of researchers assessed that it was important to conduct a survey of tourism managers and employees in Samarkand, Uzbekistan using the framework of institutional economics, to determine their attitudes toward the current crisis in the tourism market created by the COVID-19 pandemic, and to suggest possible solutions. Institutions were defined as, "organizational solutions adopted in society, informal and formal rules of functioning", and "rules of the game" (North, 1990; Williamson, 1985). Institutions that are defined in this way can be observed as part of the tourism market through an analysis of the relationship between the main participants of this market, the specificity of the relationship between industry and public structures (company versus state) and between the entrepreneurs themselves (company versus company).

Firstly, a computer-based survey was developed by the researchers. Due to the pandemic restrictions, the survey was conducted online using the Google Forms platform. The survey was prepared in both Russian and English languages that contained four major sections:

(1) Immediate reactions to the pandemic's influence on tourism (11 questions).

(2) Short-term recovery plans for tourism businesses (3 questions).

(3) Long-term challenges for tourism businesses (7 questions).

(4) Socio-demographic characteristics of respondents (5 questions).

Next, a pilot survey was administered to several respondents between April 18 and April 23, 2020. Based on feedback from the respondents a number of improvements were made in regard to the language of the questions, and the number and the meanings of several question choices were changed.

The researchers used their own contact bases to approach several institutions in Uzbekistan to assist with the survey distribution, and forwarded the revised computer-based survey to the email addresses of selected respondents between April and June, 2020. The total number of answers that were returned and deemed to be acceptable was 84 completed surveys. Seven surveys were excluded from the analysis (several respondents were not employed in the tourism industry, while several other respondents did not have any connections with Central Asia). The geographical scope of the research was intentionally limited to Samarkand city. 
The survey design allowed the participants to complete their answers by completing the section after the question, such as, "After the end of pandemic crisis I plan to..." and if the participant chose to "quit the tourism business' they were offered a further question about what were their future plans after leaving the tourism industry, and were not asked questions from other sections of the survey. Of the 77 valid answers, only one person decided to leave their tourism business reducing the final total of responses to 76. Frequency distributions for all questions were calculated. Due to the sample limitations and the specificity of this case-study, the analysis was limited to a descriptive methodology.

\section{RESULTS}

The survey responses were balanced in terms of gender (51\% - female; $49 \%$ - male). The dominant age group was in the age range 37 to 50 years $(40 \%)$, together with the age group 26 to 36 years and when combined made up $78 \%$ of all respondents. General Managers and owners of tourist companies dominated the responses $(60 \%-$ managers and owners) while others (40\% - employees) indicated that they are employed in the tourism industry.

The first question identified the scope of emotions evoked by the pandemic and the main influences on the tourism industry. In total, 187 emotional responses were submitted with fear, dismay and despair dominating the responses (41\%). Confusion was also a popular answer (18\%). Conversely, over $60 \%$ of respondents included more positive responses that were connected with 'mobilization and energy to take action' (see Figure 2 ). This suggests that tourism managers are ready to take initiatives for ways to overcome the pandemic crisis. Priority was given to undertaking activities for the survival of the company (75\%), and for the staff (50\%). However, $43 \%$ considered that it may be necessary to suspend business operations in the future if the situation did not improve. Almost half of the respondents $(46 \%)$ stated that they planned to look for additional work as a complementary source of income.

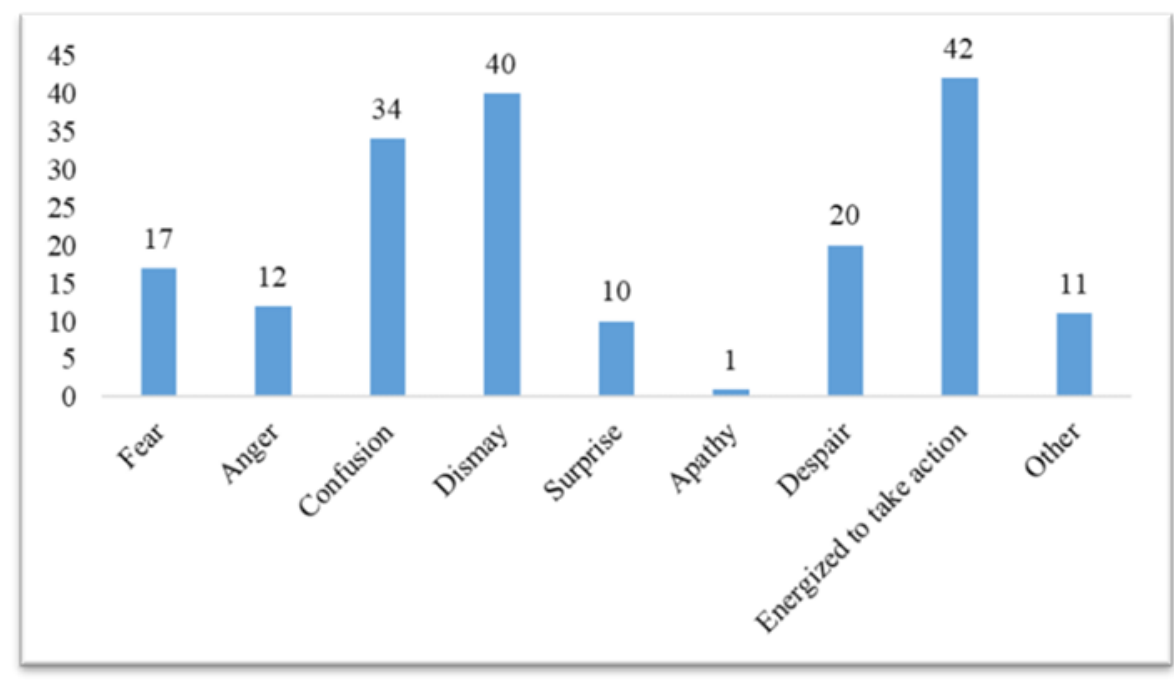

Figure-2. Emotions towards company's situation due to the COVID pandemic.

The second question referred to working at home. Respondents felt that overall, they were well prepared to work at home. Of all the problems that they listed only $9 \%$ stated that they had experienced problems with either equipment issues or self-preparedness (adaptation) to online work. Other problems were stated in the following order - customer attrition (22\%), payment issues (17\%) and disruptions to strategic plans (16\%).

The third question was related to handling problems associated with the pandemic. The majority of respondents $(58 \%)$ believed that they, as managers of tourist companies preferred to handle their own pandemicrelated business problems on an individual basis, while $42 \%$ preferred to work in a team with their colleagues from the same industry, or associations that brought together professionals from a similar occupation. Only $14 \%$ of survey respondents reported that they had contacted any of their colleagues outside their own business in the 
month previous to the survey, or had not contacted them at all. Just over a third (35.1\%) stated that they had attempted to keep up existing contacts on a daily basis. Independent internet searching and social media were considered to be the best means of obtaining information about the current state of the tourism industry and the effects of the pandemic.

The fourth question asked about where the tourism industry expected to obtain help in the future A total of $58 \%$ of respondents indicated that it should come from the government of Uzbekistan. On the other hand, $41 \%$ indicated that they expected help from professional associations (See Figure 3).

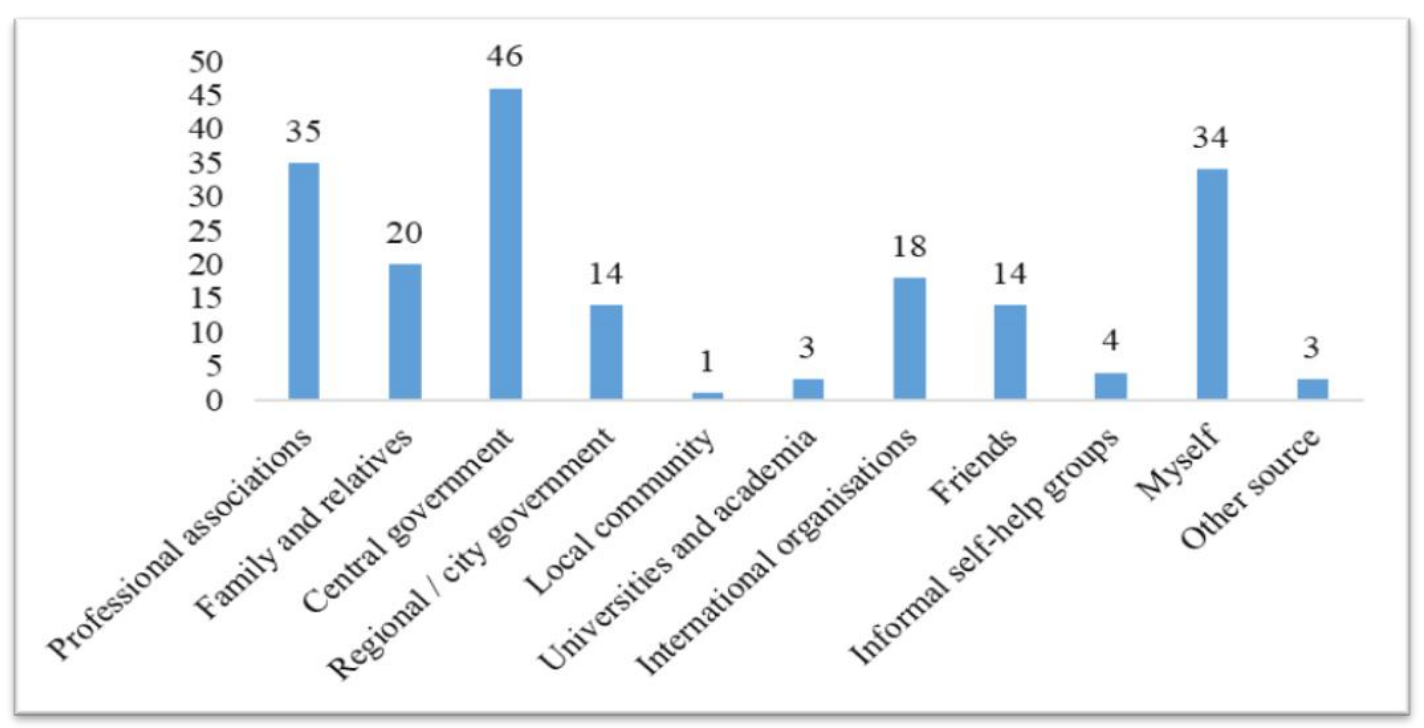

Figure-3. Expected sources of help.

For $44 \%$ of respondents, it was necessary for them to significantly expand cooperation (including foreign partners or as part of public-private partnerships). Among the goals of cooperation, qualitative changes were indicated including building the reputation of Uzbekistan companies and improving their reliability which was a necessary condition for the recovery of customers (See Figure 4).

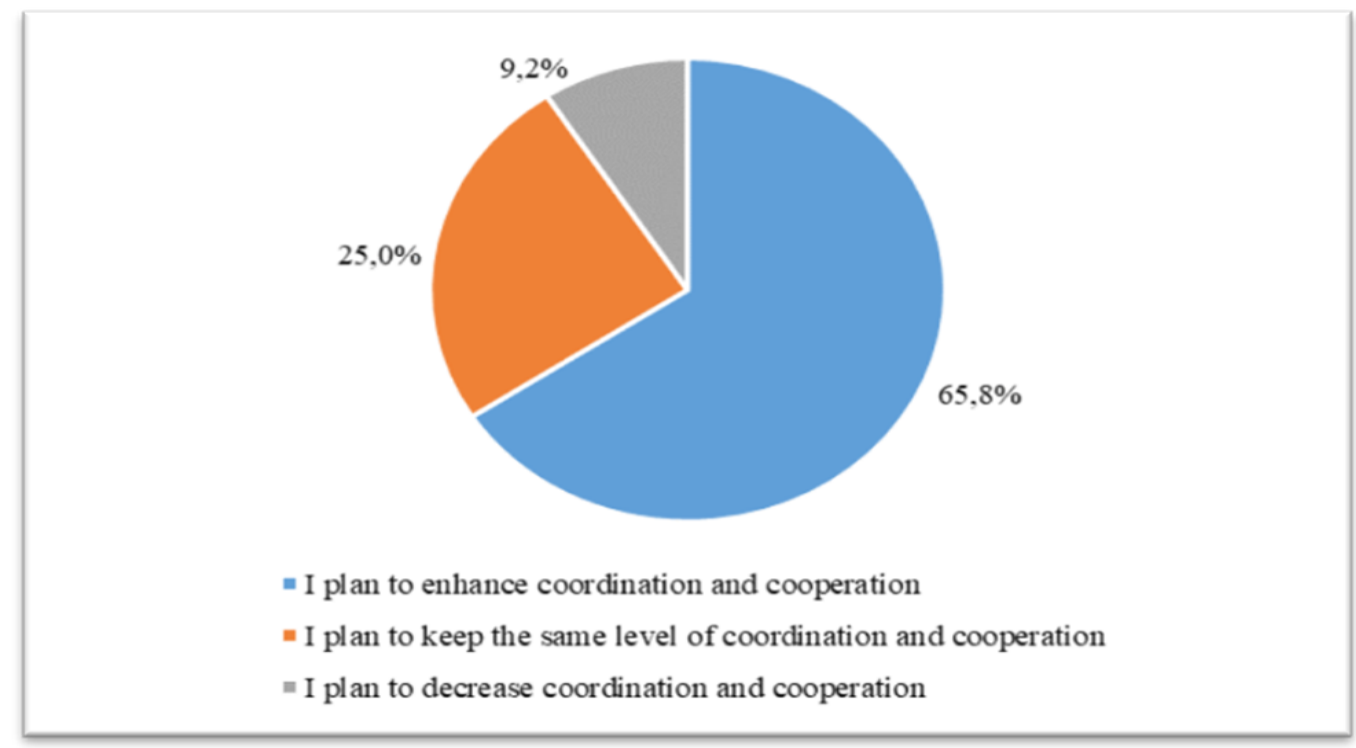

Figure-4. Respondents' plans regarding cooperation (percentage of selected answers).

The fifth question related to the most common forms of communication. The most common were text messages $(27.6 \%)$ and phone calls $(25.2 \%)$. Videoconferencing and webinars also enjoyed sizable popularity $(47.4 \%$ and $25 \%$ 
respectively) which was due to employees not being able to travel because of quarantine restrictions. The least trustworthy information sources were the radio, newspapers and journals/weekly magazines. The lowest rating from respondents was listening to the radio, while the option of undertaking independent research on the Internet was considered to be the most popular.

For the sixth question, respondents were asked to evaluate several statements from a long-term perspective about the future of tourism activities in their city, as well as several general statements about the future of tourism. (See Table 1). In general, respondents tended to demonstrate a unified approach however there was a high level of uncertainty about the possible changes for the length of tourist stay in their cities, their share of domestic tourism as well as the future role of air travel.

Table-1. General statements about the future of tourism in Samarkand city.

\begin{tabular}{l|c|c|c}
\hline Statement & Will Increase & Will Decrease & Unchanged \\
\hline Length of tourist's stay in your city & 18.4 & 56.6 & 25.0 \\
\hline Arrivals from distant countries & 10.5 & 81.6 & 7.9 \\
\hline Domestic tourism & 43.4 & 39.5 & 17.1 \\
\hline The role of health security & 85.5 & 3.9 & 10.5 \\
\hline The role of the Internet & 78.9 & 5.3 & 15.8 \\
\hline The role of air travel & 39.5 & 47.4 & 13.2 \\
\hline Amount and time taken at border checks & 65.8 & 17.1 & 17.1 \\
\hline
\end{tabular}

At the time when the survey was conducted (April, 2020), two-thirds of respondents (65\%) estimated that the financial losses to tourism companies would be greater than $50 \%$. In regard to the anticipated changes to the delivery of tourism, $45 \%$ considered that the Internet was likely to replace 'real' travel, while $61 \%$ expected that hybridization (combining a real journey with internet travel) will become more popular.

As many as $64 \%$ expected that here will be significant changes, and that tourist traffic to Uzbekistan would in the future be dominated by niche tourism, with only $13.3 \%$ believing that mass tourism will continue to remain the same as previously. A total of $45.3 \%$ expected new travel rules (e.g., strict sanitary regulations, different border controls) would be needed, however $30 \%$ believed that the travel industry would soon revert back to its old habits. In regard to the future behavior of the younger generation, it was generally expected that younger people will travel more than the current generation, but according to different, as yet unknown rules and methods. By contrast, $24 \%$ of respondents expected young people to travel less than before.

The final question related to the level of trust in international tourist organizations. An interesting trend that emerged was the respondent's belief and trust in international solutions, including those that were advocated by international organizations such as UNWTO. Only $9 \%$ believed that increasing the role of national governments would be a good solution, while the majority (64\%) believed that both solutions - an increase in the importance of the country's government, and trust in the effectiveness of international associations should co-exist together.

\section{DISCUSSION OF RESULTS}

\subsection{Reactions to the Pandemic}

The initial reactions were felt by employees in the tourism industry in Samarkand were fear, dismay and despair that dominated the respondent's responses (41\%). This supports the study by Aslam et al. (2020) who reported that the main emotions evoked by news headlines about the COVID-19 pandemic were fear, trust, anticipation, sadness, and anger. This may have been because at this time, little was known about the effects of its chronic nature and the lack of success in finding a cure. Confusion was also a popular answer (18\%). The Mayo Clinic Health System (2020) supported feelings associated with shock, confusion and disbelief that people felt as a result of the sudden onset of the pandemic. 
However, more than $60 \%$ of the respondents stated that they were also mobilized and energized to take action as a result of the pandemic. This statement relates to positive anticipation for the future (of tourism). Companies were now finding that inertia was clearly riskier than taking immediate action, so there was a need to mobilize to address the immediate threat and to take on more abstract challenges such as digital technology, automation, and artificial intelligence (McKinsey, 2020).

\subsection{Working At Home during the Pandemic}

These findings suggest that working from home was not a major problem because many employees are already part of the working from home movement. Cohen in 'The Conversation' (May 15, 2020) has forecast that in the future, the pandemic is likely to further accelerate the ongoing 'working from home movement' and this will persist long after the pandemic is over.

\subsection{Communication with Work Colleagues during the Pandemic}

The majority of respondents $(58 \%)$ believed that they, as managers of tourist companies preferred to handle their own pandemic-related business problems on an individual basis. This was a contrary finding as modern business research has suggested that working in teams is a far more effective method of handling problems associated with the COVID-19 pandemic. D'Auria and De Smet (2020) stated that the massive scale of the outbreak and its sheer unpredictability and uncertainty has made it very challenging for executives to respond to this crisis.

During this type of crisis which is characterized by uncertainty, the authors suggested the need to relinquish the belief that a top-down response will engender stability, as leaders now face problems that are unfamiliar and poorly understood. One approach they suggested is to organize a network of teams that will assist leaders to problem solve, and to quickly implement decisions while under highly stressful, chaotic conditions. A network of teams consists of a highly adaptable assembly of groups that are united by a common purpose, to work together in a similar way to individuals cooperate on a single team. Such a hypothetically considered solution could be considered a significant institutional change to a given market.

\subsection{Help During/After the Pandemic}

Responses from almost $60 \%$ of respondents stated that help should come from the government of Uzbekistan, while $40 \%$ suggested that they expected help from professional associations. In situations such as when a global pandemic occurs, urgent responses for help generally come from Federal/National governments with assistance from organizations such as the World Bank. In regard to helping the tourism industry, the OEDC (2020) has suggested several measures that governments and industry can do together such as lifting travel restrictions to restore traveller confidence and to prepare comprehensive tourism recovery plans.

Local government in Samarkand Regional Government (2020) has taken urgent steps to cope with such issues as increased unemployment, the creation of new jobs, the re-organization of the capabilities of tourism, helping small businesses, etc. Over 54 investigation projects have been approved for 2020-2021 in order to support the portfolios of tourism and labor in the region, and 1321 new jobs have been created. Despite the pandemic, many projects under the region's authority have continued. Permits were given to start construction of 24 properties, and six hotels have reopened in the first half of 2020.Although there have been some problems, six new tourist minibuses were purchased by commercial tourism providers with assistance from government grants to allow travel to 11 popular touristic locations. In addition, the services of 11 tour operators were re-established, and five hygienic health-caring shops were allowed to remain open for 24 hours duration (Samarkand Regional Government, 2020). 


\subsection{Communication Patterns}

The most common forms of communication during this pandemic were instant messaging (27.6\%) and phone calls (25.2\%). Dialog (2020) stated that although traditional forms of communication such as phone calls and emails can help, text messaging is the best form of communication during an emergency such as in a pandemic, natural disaster, severe weather or extended power outrage. Texting is a proven method for quickly reaching and successfully engaging with employees and providing them with the latest information and policies as they navigate a crisis.

\subsection{Future Tourism Trends}

Almost half (45\%) of the respondents considered that the Internet might replace 'real' travel, while $61.3 \%$ expected that hybridization would become more popular. There is little doubt that COVID-19 has increased the use of the internet to connect with others, share information and resources, and to devise collective solutions to urgent problems during COVID-19 (Roose, 2020). Some travellers have turned to virtual reality (VR) to take them on virtual overseas adventures because they cannot travel because of COVID-19. The potential for this type of technology has several advantages such as reducing tourism's carbon footprint as well as ecological benefits such as cleaner air and water. Virtual travel experiences are now seeing a surge in popularity, particularly from educators and those working in nursing homes (Chen, 2020). However, several academics have forecast that it will never replace real travel. Philosopher Robert Nozick stated that, "I do think that there are some kinds of tourist experiences where the value in them is in the doing, not just in the seeing and hearing, and it'll be tough for VR to replicate."

Almost two-thirds of respondents (64\%) stated that they expected that here will be significant changes to the tourism industry, and that tourism in the future will be dominated by niche tourism, while only $13 \%$ believed that mass tourism will continue at the same level as before COVID-19. This is because the effects of mass tourism have been shown to be detrimental to a community as local culture, authenticity and resources are often depleted. Even after the lockdowns have begun to ease and international travel restrictions are being relaxed, and after months of social distancing it is expected that the appeal of an overcrowded beach or a hotel resort will not be as popular as previously.

There is a clear scope that niche travel themes which were beginning to emerge pre-Covid-19 will be considerably more important for future travel (Airport Industry Review, 2020). Futurologists also noted for example Froyd (2020) that there is a growing need to establish a more personalized and targeted marketing approach that needs to be different from concentrating on mass tourism, and to seek out more specialized niche markets.

Almost half $(45 \%)$ stated that they expected that there will be new travel rules (such as strict sanitary regulations, different types of border controls) implemented, however $30 \%$ believed that the travel industry will soon revert back to its previous rules and regulations that existed before the COVID-19 pandemic. As expected, preventative measures and restrictions have been put in place for international travellers to Uzbekistan (Official Global Travel Advisories, 2020). These measures may vary depending on the region, and include: (1) following the instructions of local authorities relating to physical distancing; (2) to avoid crowded areas; and (3) you must wear a mask covering your face in public spaces. A warning will be given that if these measures were violated, fines criminal charges may be introduced for endangering public health.

Most respondents (54\%) stated that they expected that younger people will travel in greater numbers in the future than the current generation, but according to different, as yet unknown rules. Studies have suggested that younger tourists tend to care more about the environment, sustainability and regenerative recreation than older generations (Robinson \& Picard, 2006). Millennials (aged between 22 and 38 years of age in 2019) make up around $30 \%$ of the world's population and are arguably the most concerned generation when it comes to environmental 
sustainability and social issues. Millennials have been forced to face the realities of extreme weather patterns, sea level rises, rapidly increasing GMO agriculture and species extinction (among others). This has created a generation of people who desire sustainability as part of their mainstream culture (Sustainability, 2018).

\subsection{Trust in International Organizations}

The UN Secretary General Antonio Guterres stated that tourism could be used as a platform to overcome the pandemic (United Nations World Tourism Organization, 2020). By bringing people together, tourism can promote solidarity and trust. Many analysts indicate that the issue of trust is currently of key importance (Center on International Cooperation, 2020). The threats of the COVID-19 pandemic are fueling the search for help from national governments rather than international institutions. For example, the latest findings of the Edelman Trust Barometer based responses from 11 countries (US, UK, Canada, France, China, Germany, India, Japan, South Korea, Saudi Arabia and Mexico) showed that there was an $11 \%$ increase in confidence in their governments since January to May 2020.

Thus, the response to COVID-19 is also a test of the ability to respond to other international threats such as climate change, the increased number of likely climate-related disasters, and cyber security. Meanwhile, these are issues that require solutions on a global scale. Hence, tourism becomes a field for verifying the ability to build trust in the modern world; and building trust is created from the lowest structures, including cities and regions.

\section{CONCLUSION}

The COVID-19 pandemic has resulted in the introduction of new, or the dissemination of previously proven solutions that regulate the relationships between participants of the tourism market. These solutions can be called institutions according to the institutional approach widely represented in the social sciences (including sociology and economics). Formal institutions are reflected in regulations and are mainly the result of the actions of lawmakers. Informal institutions result from the traditions and beliefs of people and are expressed in their customs and behavior, including those related to business relationships.

This paper has identified a number of institutions that are being used as a response to the pandemic: additional forms of state support for entrepreneurs, consultations with entrepreneurs, webinars, extraordinary support for new investment projects, the preparation of post-crisis measures, actions aimed at improving the product (e.g., a week of the medical tourism sector or cultural tourism), campaigns aimed at marketing (passports for tourist facilities) and others.

In conditions of crisis, it is expected that different market entities will look for new ways and rules to survive in difficult times. In particular, entrepreneurs and owners of hotels, restaurants, travel agencies, guides and interpreters who are most at risk due to the drastic reduction in tourist traffic, should be interested in securing the support of public institutions. The way forward that is leading to such support could be integrated into presentations and support for the industry. Generally, it can be stated that in case of Uzbekistan and the city of Samarkand such actions did not take place, although in the survey, $60 \%$ of respondents declared that they were ready and mobilized for support by government agencies.

In this unique, highly touristic city of Samarkand, many of the owners of tourist organizations expected that this city would undertake expressive actions (including new institutions), based on the strength of the tourism industry (there are 350 hotel and accommodation facilities in Samarkand, which is approximately $30 \%$ of all facilities in the country). This study has shown that there are weaknesses in the structures that represent industry. This is confirmed by the opinion of representatives of the city hall and the manner in which activities were conducted (i.e., individual contacts with selected partners and not with the Hotelier's Association). This indicates that the style of decision-making management is similar to what was previously established in the Soviet era. The durability of such a situation, 30 years after the dissolution of the USSR and the gaining of independence by 
Uzbekistan, may puzzle many people. This may have resulted from both the authoritarian tendencies of the different layers of bureaucracy, but also from the unwillingness of entrepreneurs themselves to be associated with government agencies. Most of the surveyed managers (58\%) believed that they preferred to solve pandemic-related business problems on their own. However, there is enormous potential to receive help from professional associations, as $41 \%$ of survey participants expected to be helped by them.

As indicated by institutional theory (Sautet, 2005) conditions for the effectiveness of regulatory actions is the coexistence and mutual support of formal and informal institutions (norms). The way to do this is to build trust between market stakeholders - both between Uzbekistan as a recipient country and tourists in the countries that are generating visits, and within a given market - between industry and authorities. Considering the interpersonal dimension of the phenomenon of trust, the greatest chance of building or regaining this trust lies at the regional and local level. In this respect, the city of Samarkand, with its resources and numerous contacts from the past, should become a leader in the process of tourism revival after the Covid-19 pandemic is over.

Funding: This study received no specific financial support.

Competing Interests: The authors declare that they have no competing interests.

Acknowledgement: All authors contributed equally to the conception and design of the study.

\section{REFERENCES}

Airport Industry Review. (2020). Niche travel trends may become more mainstream in the future travel space. Retrieved from: https://airport.nridigital.com/air_may20/travel-trends-2020.

Aslam, F., Awan, T. M., Syed, J. H., Kashif, A., \& Parveen, M. (2020). Sentiments and emotions evoked by news headlines of coronavirus disease (COVID-19) outbreak. Humanities and Social Sciences Communications, 7(1), 1-9. Available at: http://doi.org/10.1057/s41599-020-0523-3.

Center on International Cooperation. (2020). COVID-19 and trust in international cooperation. Retrieved from: https://cic.nyu.edu/publications/covid-19-and-trust-international-cooperation. [Accessed March 15, 2021 ].

Chen, A. (2020). Is virtual travel here to stay, even after the pandemic. National Geographic. Retrieved from: https://www.nationalgeographic.com/travel/2020/04/can-virtual-reality-replace-real-tourism-during-pandemic-andbeyond/.

Coase, R. H. (1991). The nature of the firm (1937). The Nature of the Firm. Origins, Evolution, and Development. New York, Oxford, $18,33$.

D’Auria, G., \& De Smet, A. (2020). Leadership in a crisis: Responding to the coronavirus outbreak and future challenges. Retrieved from: https://www.mckinsey.com/business-functions/organization/our-insights/leadership-in-a-crisisresponding-to-the-coronavirus-outbreak-and-future-challenges.

Dialog, H. (2020). Emergency, mass texting alerts. Retrieved from: https://www.dialoghealth.com/emergency-group-masstexting-covid.

Encyclopedia of the Nations. (n.d). Retrieved from: https://www.nationsencyclopedia.com. [Accessed March 15, 2021 ]

Froyd, J. (2020). Tourism after COVID-19: Scenerios and solutions. Tourism Review News. Retrieved from: https://www.tourism-review.com/tourism-after-pandemics-safety-first-news 11563.

Global Economic Prospects Report. (2020). Subdued global economic recovery. Retrieved from: https://www.worldbank.org/en/publication/global-economic-prospects. [Accessed March 13, 2021 ].

Mayo Clinic Health System. (2020). COVID-19 and your mental health. Retrieved at: https://www.mayoclinic.org/diseasesconditions/coronavirus/in-depth/mental-health-covid-19/art-20482731.

McKinsey, Q. (2020). Reimaging the post-pandemic organization. Retrieved from: https://www.mckinsey.com/businessfunctions/organization/our-insights/reimagining-the-post-pandemic-organization.

North, D. C. (1990). Institutions, institutional change, and economic performance. New York: Cambridge University Press. 
Journal of Tourism Management Research, 2021, 8(1): 88-100

OEDC. (2020). Tourism policy responses to the coronavirus (COVID-19). Retrieved at: https://www.oecd.org/coronavirus/policy-responses/tourism-policy-responses-to-the-coronavirus-covid-196466aa20/.

Official Global Travel Advisories. (2020). Uzbekistan. Retrieved from: https://travel.gc.ca/destinations/uzbekistan

Robinson, M., \& Picard, D. (2006). Tourism, culture and sustainable development. Paris: UNESCO.

Roose, K. (2020). The coronavirus crisis is showing us how to live. Retrieved from: https://www.nytimes.com/2020/03/17/technology/coronavirus-how-to-live-online.html.

Samarkand Regional Government. (2020). Influence of the coronavirus pandemic on tourism. Unpublished report of Department of Tourism Development. Samarkand, Uzbekistan.

Sautet, F. (2005). The role of institutions in entrepreneurship: Implications for development policy. Arlington, VA: Mercatus Center.

Sustainability. (2018). Do millennial consumers really care about sustainability? Retrieved from: https://sourcingjournal.com/topics/sustainability/millennial-consumers-really-care-sustainability-80072/.

United Nations Development Program. (2020). COVID-19 and the SDGs. Retrieved from: https://feature.undp.org/covid-19and-the-sdgs/.

United Nations World Tourism Organization. (2020). Tourism can be a platform for overcoming the pandemic. By bringing people together, tourism can promote solidarity and trust. UN Secretary-General Antonio Guterras. Retrieved from: https://www.unwto.org/news/tourism-can-promote-solidarity-un-secretary-general-antonio-guterres. [Accessed March 12, 2021].

Veblen, T. (1899). The theory of the lesiure class. An economic study of the evolution of institutions. New York: Macmillan.

Williamson, O. E. (1985). The economic institutions of capitalism. New York: The Free Press.

Views and opinions expressed in this article are the views and opinions of the author(s), Journal of Tourism Management Research shall not be responsible or answerable for any loss, damage or liability etc. caused in relation to/arising out of the use of the content. 